\title{
Let's tie circumferences up, so we count them all. An unconventional combinatorics problem in compulsory secondary school
}

DOI: $10.46932 / \mathrm{sjjdv} 3 \mathrm{n} 1-085$

Received in: Jan 30st, 2021

Accepted in: Feb 1th, 2022

\author{
Aitzol Lasa \\ $\mathrm{PhD}$ in Mathematics, specialty in Mathematics Education \\ Public University of Navarre, Spain (UPNA) \\ Department of Statistics, Computer Science and Mathematics. Las Encinas Building. Campus Arrosadia \\ s/n. 31006 Pamplona, Spain \\ E-mail: aitzol.lasa@unavarra.es \\ Miguel R: Wilhelmi \\ $\mathrm{PhD}$ in Mathematics, specialty in Mathematics Education \\ Public University of Navarre, Spain (UPNA) \\ Department of Statistics, Computer Science and Mathematics. Las Encinas Building. Campus Arrosadia \\ s/n. 31006 Pamplona, Spain \\ E-mail: miguelr.wilhelmi@unavarra.es

\section{Jaione Abaurrea} \\ Master's Degree in Secondary Education Teaching \\ Universidad Pública de Navarra (UPNA) \\ Public University of Navarre, Spain (UPNA) \\ Department of Statistics, Computer Science and Mathematics. Las Encinas Building. Campus Arrosadia \\ s/n. 31006 Pamplona, Spain \\ E-mail: jaione.abaurrea@unavarra.es
}

\begin{abstract}
Secondary school students (age 13-14) solve a combinatorial task in the Mathematical Olympiad, whose answers are analyzed and discussed using theoretical tools from two didactical frameworks: on one hand, the Onto-semiotic Approach (OSA), and, on the one hand, the Theory of Didactic Situations in Mathematics (TDSM). The statistical study is carried out by tools from Statistical Implicative Analysis (SIA). Results express that most participants possess sufficient arithmetic strategies to solve the task, without turning to combinatorial algebra. At the same time, the algebraization level shown by these same participants in their answers to other tasks of the Olympiad, is strongly correlated to their behaviors in the combinatorial task, and so, a student who masters an algebraic technique is also aware of the limitations of its field of application. Therefore, adaptability is a key element in the analysis of the observed strategies and their success rate.
\end{abstract}

Keywords: Combinatory, algebraization levels, adaptation to a mathematical context, implicative analysis. 


\section{INTRODUCTION}

The organization of the Secondary 2-level (age 13-14) Mathematical Olympiad is problematic from the point of view of the mathematical contents that should be selected for the test. Geometry, along with arithmetic and measurement, are topics that are naturally included, since the Spanish curriculum takes into account these topics into specific content blocks. The same cannot be said for logic (problemsolving activities) and chance (combinatory and probability). Moreover, the resolution of such problems has a high degree of difficulty, even for students from higher education. However, these problems provide very attractive challenges, which are highly appreciated by students. It is thus a counter to the perception that "mathematics is boring" (Saragosa and Ferreira, 2020). In other words, the difficulty of the challenge, in a non-school context, establishes conditions of enjoyment for students.

This paper focuses on a combinatorial task and the answers that Olympiad participants gave to that task. Most participants mobilized a repertoire of fundamental strategies based on counting and on the analogical representation of all cases; participants also used algebraic and symbolic representations at different levels of algebraization (Godino, Aké, Gonzato \& Wilhelmi, 2014; Godino et al., 2015; Godino, Wilhelmi et al., 2015). The type of problem posed and the resolution strategies used do not correspond to conventional teaching materials, namely textbooks and pre-made worksheets with stereotyped tasks (Arévalo, Guzmán and Sánchez, 2021).

All data has been processed by Descriptive Statistical tools and Statistical Implicative Analysis (Gras et al., 2008) software in order to obtain results, and theoretical tools from the Onto-Semiotic Approach (OSA) (Font, Godino and D'Amore, 2007) and the Theory of Didactical Situations in Mathematics (TDSM) (Brousseau, 1997; 2007) have been used in order to discuss them. These results show that the observed counting procedures and the participant's success rate in the execution of the task justify the introduction of combinatorial problems in the first years of Compulsory Secondary Education. Finally, some conclusions also arise regarding the progressive acquisition of algebraization levels by students.

\section{THEORETICAL FRAMEWORKS}

The Onto-semiotic Approach of Mathematical Knowledge and Instruction (OSA) places operative and discursive practices at the center of mathematical activity and its analysis (Font, Godino and D’Amore, 2007; Contreras, Ordoñez \& Wilhelmi, 2010). In the early educational stages, in tasks of counting, materialization is essential, as students count particular objects or their ostensive representations. In this way, they assign personal meaning to combinatory by routine counting tasks, 
where effectiveness implies the correct application of basic counting principles (no element remains without counting, no element is counted more than once).

Thereafter, when tasks involve a high number of cases, ostensive representation is inadequate or too costly. There is a breach on the didactical contract, as objects are no longer accessible to counting, requiring basic non-ostensive counting procedures, where generalization and the use of intensive representations are necessary. These needs are not obvious from student's point of view, nor are they exempt of conflict. "Each [resolution] method quickly becomes complex and uncertain when the size of the collection increases, while the next method does not yet present clear efficacy" (Brousseau, 2007, 42). Thus, the transition from one strategy to another is not linear (Figure 1).

Figure 1. Regular learning progression, without informational leaps (Brousseau, 2007, 43).

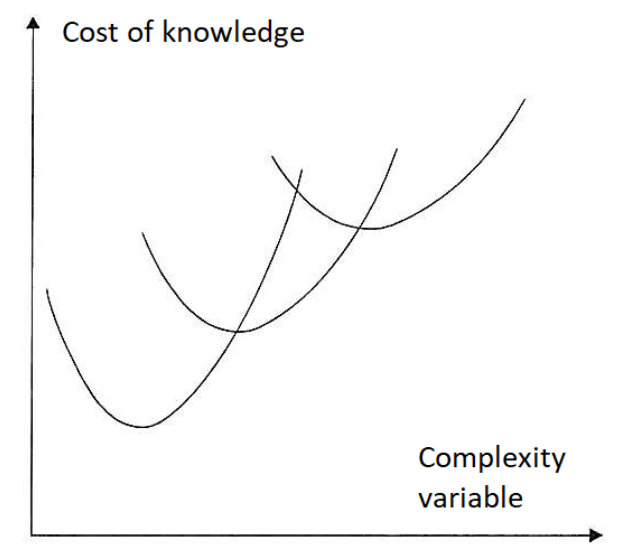

In the case of Combinatory, this regular progression takes place in the shift from the use of explicit techniques (count all cases) to implicit techniques (use of rules, calculations and arguments). Thus, mathematical practice leads to formulas and algorithms. This is when the institutionalization of the notions of permutation, variation and combination, as effective instruments of counting classes of problems, is relevant (Wilhelmi, 2004).

Figure 2 summarizes this process involving the following dualities:

- Ostensive / non-ostensive. From the counting of physical objects or their representations (by a comprehensive materialization of all cases), situations are counted without the constructive counting of all cases (by a process of idealization through schemes, metaphors or clusters).

- Extensive / intensive. From the individual counting of small sets, students identify rules for the formation of families of cases, involving processes of particularization (concretion of the rule in a particular case) and generalization (identification of the common pattern of several specific counting). 
- Personal / Institutional. Personal meanings serve as a basis for the motivation of institutional meanings, which in many cases involve the determination of formulas that model classes of situations.

Figure 2. Combinatory or systematic counting as operational and discursive practice.

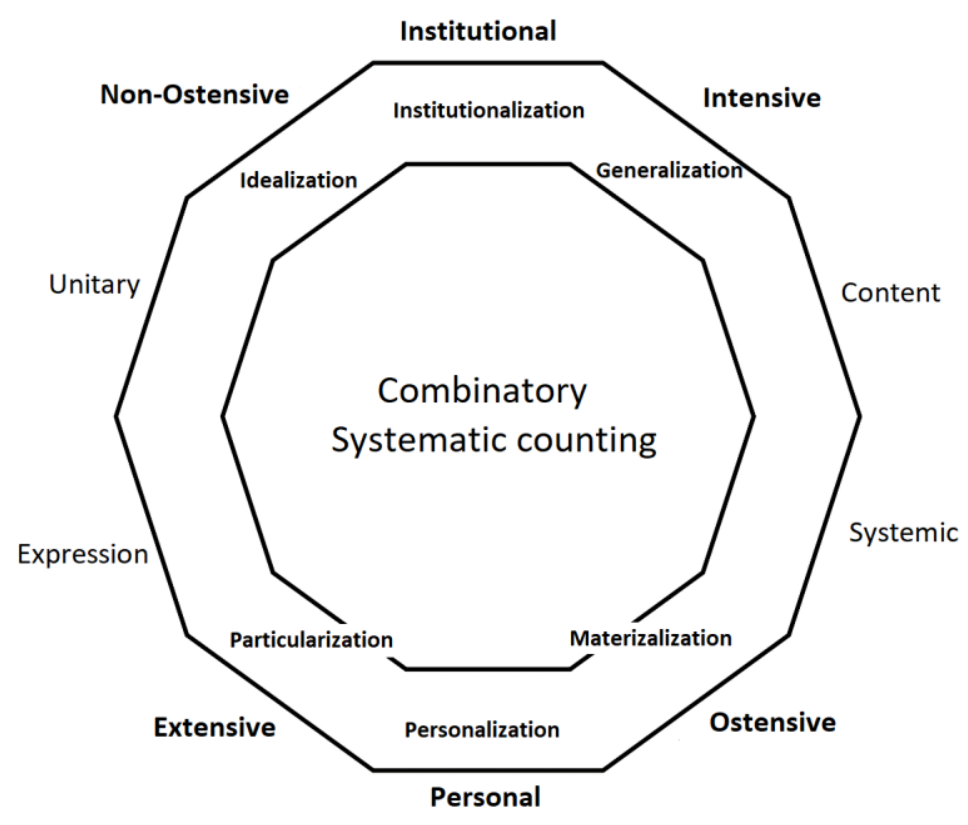

The generalization process is closely linked to the use of intensive practices with an essential algebraic component. OSA distinguishes different levels of algebraization (Godino, Aké, Gonzato \& Wilhelmi, 2014) from level 0 (exclusively arithmetic procedures in the absence of algebra) to level 3 (consolidation of algebra), going through level 1 (incipient, intensive in structural tasks) and level 2 (intermediate, use of variables but there are no operations with them). Thus, the identification of the algebraization level shown by students is a variable that will have to be taken into account in the analysis of the participants' accomplishments.

\section{A PRIORI ANALYSIS}

The introduction of a combinatorial or probability problem in the Mathematical Olympiad is justified by the general objectives of the stage. In fact, the first and second courses of Secondary Education should promote, among others, the formulation of conjectures, the recollection and organization of information in tables and diagrams, and the counting of absolute and relative frequencies, in relation to simple random phenomena (MEC, 2015). It also promotes the resolution of problems from everyday life "according to the ways of mathematical activity, such as the systematic exploration of alternatives" (p. 
752), showing a positive attitude that allows the student "to enjoy the creative, manipulative, aesthetic and utilitarian aspects of mathematics" (p. 752).

Thus, although the official curriculum of the second course of Secondary Education does not propose a specific section of combinatorial content, there is no limitation to promote problems whose resolution requires a case-counting activity. In fact, combinatory as the set of strategies for the implicit counting of cases without excess or default (Wilhelmi, 2004), is an appropriate context for the systematic exploration of alternatives, the formulation of conjectures, the implementation of diverse methods of resolution and the analysis of their effectiveness.

Combinatorial tasks are complex in all educational stages. Proof of this is that university students with high mathematical preparation face the same difficulties as high school students without specific instruction in the subject, in solving some problems for which sophisticated mathematical knowledge is not needed at first sight (Roa, Batanero \& Godino, 2001). Moreover, textbooks do not present tasks that really promote the acquisition of combinatorial content, leaving the study of the combinatorial topic isolated (Espinoza \& Roa, 2013). Thus, its teaching focuses on showing a class of stereotyped situations that require two single steps: (a) determining the type of problems (permutation, variation or combination, with or without repetition); (b) calculation using a formula.

Indeed, an early institutionalization of the algebra of combinatory, i.e. the use of intensives (algorithms for counting ideal cases) in the absence of a personal meaning assigned to the counting process, seems to be responsible for this failure. Therefore, problem-solving strategies, systematic enumeration and the use of tree diagrams, without the corset of combinatorial formulas and without formalist ties, should be enhanced.

Therefore, in the analysis of responses by participants of the Mathematical Olympiad, the following questions can be asked according to the competence shown:

- If a participant counts all cases, what basic rules of numbering, addition and multiplication are observed in the resolution?

- If a participant does not count all cases, what kind of intensives does she use to face the task?

In addition, the possible relationship between the two variables is investigated, 1) "Solution of the combinatorial problem", and 2) "Algebraization level shown in the test"; establishing the following conjecture: There is a high correlation between the level of algebraization shown by the participants and the efficacy in the case-counting tasks. 


\section{THE PROBLEM}

All participants are given four indistinguishable laces with which to experiment, which can be knotted in multiple ways, before moving on to the symbolic analysis of the situation. Thus, the ostensive dimension is potentiated with manipulative material (Arimatéa \& Souza, 2013):

"Abel and Belem invent a game. They have four laces, and Abel takes them in her fist (Figure 3). The ends of the laces are visible, both at the top and bottom. However, there is no way of knowing which lower end corresponds to each upper end. Next, Belem ties the ends up, knotting them two by two: two knots on the top, two on the bottom. Finally, Abel releases the laces:

- If the laces appear in separate ties, Abel wins the game.

- If the laces appear in a single tie, Belem wins the game.

Which of the two is most likely to win? Abel or Belem?"

Figure 3. Arrangement of the laces.

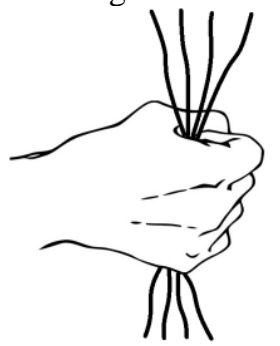

The way laces A, B, C and D tie at the top does not have any influence in the resolution. It is therefore considered a particular tie, $\mathrm{AB}$ (which necessarily implies a $\mathrm{CD}$ tie). Abel only wins in case she ties the same laces at the bottom, A'B'(C'D'), while Belem has two cases in favor: A'C'(B'D') and A'D'(B'C'). Hence, Abel wins with a probability of 1/3, while Belem has two times that probability, 2/3.

\section{RESULTS}

Only one tenth of the participants misinterpret the statement, suggesting that the purpose of the problem is well adjusted to the degree of difficulty for the educational stage. Table 1 summarizes the observed behaviors and types of resolution. 
Table 1. Types of observed resolutions

$\begin{array}{lll}\text { RES1 } & \text { Correct interpretation of the statement } & 90 \% \\ \text { RES2 } & \text { Explains the reasoning in a written speech } & 54 \% \\ \text { RES3 } & \text { Use of tables for case counting } & 18 \% \\ \text { RES4 } & \text { Use of analogic representation of laces } & 41 \% \\ \text { RES5 } & \text { Plays the game (empirical study) } & 5 \% \\ \text { RES6 } & \text { Answer by global intuition on the statement } & 50 \% \\ \text { RES7 } & \begin{array}{l}\text { Counting of all cases } \\ \text { RES8 }\end{array} & \begin{array}{l}\text { Performs some kind of implicit counting, such as } \\ \text { the use of arguments or calculations to obtain all }\end{array} \\ & \begin{array}{l}\text { favorable cases } \\ \end{array} & \\ & \end{array}$

The most widespread type of resolution contains analogic representations in two dimensions of the laces, a description of the counting process and a written explanation of the reasoning. Participants first count all cases and then give an answer to the problem, depending on the number of cases favorable to one player or another (Figure 4).

Figure 4. Analogic representations and systematic counting of all cases, without (a) or with (b) words

(a) Systematic counting of all cases, without words

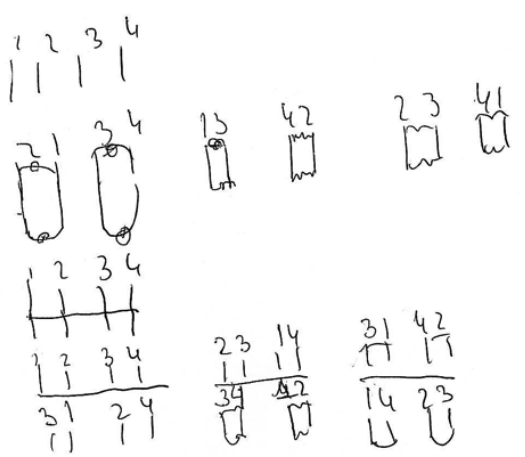

(b) Systematic counting of all cases, with words

$$
\text { Belén tiene más posibilidades de ganar porque: }
$$

- Posibilidades de ABel

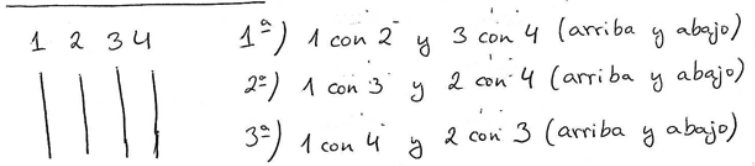

- Posibilidades de belén:

\begin{tabular}{|c|c|c|}
\hline $\begin{array}{lll}1 & 2 & 34\end{array}$ & 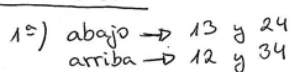 & $2 \Rightarrow$ Invertir la 19 \\
\hline & $\begin{array}{l}\text { 3) abajo } \rightarrow 13 \text { y } 24 \\
\text { arriba } \rightarrow 14 \text { y } 23\end{array}$ & 4a) Invertir la 3a \\
\hline & 5) $\underset{a \text { abajo } \rightarrow 14}{a}$ y 23 & $6 \Rightarrow$ ) Invertir la 5= \\
\hline
\end{tabular}

TRANSLATION (b)

\begin{tabular}{|c|c|}
\hline $\begin{array}{l}\text { "Belem has more options to win because: } \\
\qquad \text { Abel's options: }\end{array}$ & 1rst) down $->13$ and 24 ; up $->12$ and 34 \\
\hline 1rst) 1 with 2 and 3 with 4 (up and down) & 2nd) down $\rightarrow 13$ and 24 ; up $>14$ and 23 \\
\hline 2nd) 1 with 3 and 2 with 4 (up and down) & 3rd) down $>14$ and 23 ; up $>>12$ and 34 \\
\hline \multirow[t]{3}{*}{3 rd) 1 with 4 and 2 with 3 (up and down) } & 4 th) reverse option 1 \\
\hline & 5 th) reverse option 2 \\
\hline & 6 th) reverse option $3^{\prime \prime}$ \\
\hline
\end{tabular}

To a lesser extent, some sort of implicit counting is made on the basis of reasoned arguments to justify the existence of more cases favorable to Abel or Belem. This type of resolution allows to find the player most likely to win, but in some cases, it does not allow to determine the associated probability (Figure 5). 
Figure 5. Table of cases and rule to find favorable cases.

TRANSLATION

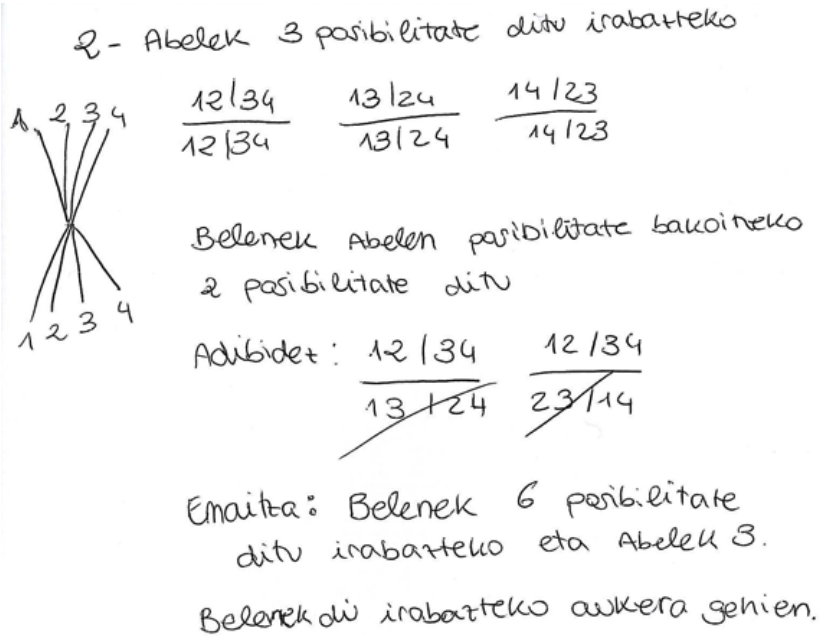

Reasoning:

"Abel has 3 chances to win. For every possibility of Abel, Belem has two chances of winning.

- gives example -

Solution: Belem has 6 chances to win and Abel has 3. Belem has more chance of winning."

Other resolutions, although not very widespread, are based on playing many matches to find the frequencies of the probability "in act" (Vergnaud, 1981) (Figure 6).

Figure 6. Empirical resolution.

El que más posibilidades de ganar tiene es Abel porque probando hemos visto que hay en atacluras separadlas

\section{TRANSLATION}

"The one who is most likely to win is Abel, because by many attempts we saw that there are more chances for the laces to appear in separate ties."

This is not a sort of problem which could be solved by consolidated algebraic calculations. Evidence of this is that $44 \%$ of participants show level 3 of algebraization along the Olympiad, while in this particular problem $26 \%$ show level 1; and 22\% level 2 (Table 2). 
Table 2. Algebraization levels.

\begin{tabular}{llll}
\hline \multirow{2}{*}{ Problem } & ALG1 & Use of arrows, codes and symbols (level 1) & $26 \%$ \\
& ALG2 & Use of variables and unknowns (level 2) & $22 \%$ \\
Olympiad & ALG3 & Shows level 3 along the Olympiad & $44 \%$ \\
\hline
\end{tabular}

Regarding the numerical field used, participants seem to have a slight preference over natural numbers (NUM1, 37\%) rather than rational numbers (NUM2, 30\%), but there is no evidence that these differences are significant.

$43 \%$ of the participants stated that "Belem wins" is more likely than "Abel wins" (COR1). Of these participants, only $13 \%$ determine the probability associated with these events (COR2).

The implicative analysis of the results generates a diagram (figure 7) in which relationships can be observed between the variables. In particular, it should be noted that variables COR1 and COR2 are strongly related to level 3 of algebraization (ALG3) and the use of the rational numerical field (NUM2).

Figure 7. Implicative analysis.

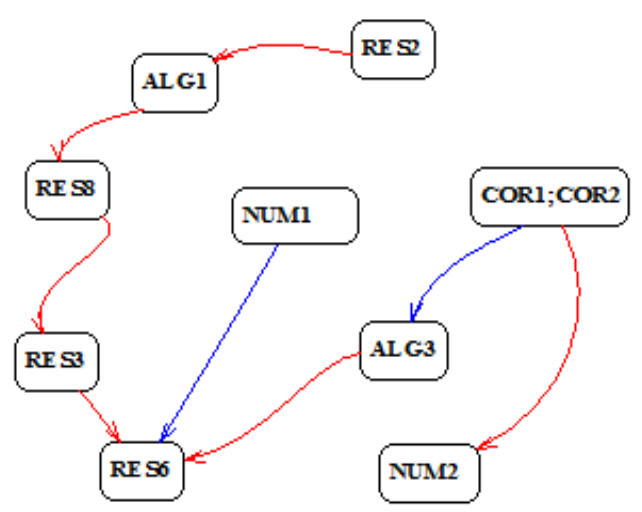

There is a chain of behaviors that have a strong relationship: participants who prioritize the written argumentation of the problem (RES2) show level 1 of algebraization (ALG1). In turn, level 1 relates to the implicit counting strategies (RES8), the implicit counting with the use of tables (RES3), and the latter with the global interpretation of the problem (RES6). However, these relationships are not transitive, a fact that reinforces that relationships are neither causal nor determine per se a criterion to place the teaching of one topic before another. Finally, the use of the natural numerical field (NUM1) is directly related to the global interpretation of the problem (RES6).

\section{DISCUSSION OF RESULTS AND CONCLUSION}

Successful participants in solving the task show a clear mastery on the rational numerical field and algebra (they show level 3 of algebraization in the remaining problems of the Olympiad). However, in the treated combinatorial problem, arithmetic strategies and counting of all cases are used, along with 
analogical representations and in the absence of complex codifications. In other words, participants who master algebra are also aware of the limitations of its use. The cost of the old technique (arithmetic) is lower than the new one (algebraic), in relation to the complexity of the task (Figure 1).

On the other hand, participants who use ordinary language and show a lower level of algebra (level 1 of algebraization in this combinatorial problem) mistakenly use implicit counting strategies that have not allowed a correct answer. This group of participants tries to solve the problem with an unconsolidated technique. Although they do not have a clear algebra mastery, they try to calculate the number of favorable cases from intensives (operations, rules and arguments).

The use of tables, and the global and intuitive interpretation of the problem, neither give good results. These participants do not divide the main problem into smaller problems. In contrast to the rational numerical field, which is linked to the variables that measure the success rate, the natural numerical field is related to this intuitive and simplistic understanding of the problem.

Thus, the study suggests that in the teaching of algebra attention should be given to: (a) the analysis of its field of use, (b) the assessment of the efficacy and cost of its associated techniques, (c) the acquisition of control strategies, in many cases based on arithmetic methods, and, finally, (d) the articulation of the different numerical fields. 


\section{REFERENCES}

Arévalo E., Guzmán H. A., Sánchez E. A. (2021). Teaching mathematics at mexican elementar schools. South Florida Journal of Development, 2(5), 6371-6381. https://doi.org/ 10.46932/sfjdv2n5-008

Arimatéa C. de, Souza E. de. (2013). Reflexôes de docentes sobre o ensino de combinatória: transitando entre conhecimento pedagógico e do conteúdo [Teachers' reflections about teaching combinatorics: transiting between pedagogical and content knowledge]. En J.M. Contreras, G. Cañadas, M. Gea y P. Arteaga (Eds.), Actas de las $1^{\text {as }}$ Jornadas Virtuales en Didáctica de la Estadística, Probabilidad y Combinatoria (pp. 555-562). Granada: Departamento de Didáctica de la Matemática (UGR). https://n9.cl/isfz3

Brousseau G. (1997). Theory of Didactical Situations in Mathematics. Kluwer.

Brousseau G. (2007). Iniciación al estudio de la Teoría de las situaciones didácticas en matemáticas [Initiation to the study of the Theory of didactical situations in mathematics]. Buenos Arires: Zorzal.

Contreras A., Ordoñez L., Wilhelmi M. R. (2010). Influencia de las pruebas de acceso a la universidad en la enseñanza de la integral definida en el bachillerato [The influence of university entrance examinations on teaching of the definite integral at High School]. Enseñanza de las ciencias, 28(3), 367-384, https://raco.cat/index.php/Ensenanza/article/view/210806

Espinoza J., Roa R. (2013). Desarrollo del tema de combinatoria presente en algunos libros de texto de matemática de educación secundaria en España [Development of the topic of combinatorics in some secondary school mathematics textbooks in Spain]. En J.M. Contreras, G. Cañadas, M. Gea y P. Arteaga (eds.), Actas de las $1^{a s}$ Jornadas Virtuales en Didáctica de la Estadística, Probabilidad y Combinatoria (pp. 181-188). Granada: Departamento de Didáctica de la Matemática (UGR). https://n9.cl/isfz3

Font V., Godino J.D., D’Amore B. (2007). An onto-semiotic approach to representations in mathematics education. For the learning of mathematics, 27(2), 2-7. https://flmjournal.org/Articles/7856D4C00321D131A92B3A9C9B7580.pdf

Godino J. D., Aké L., Gonzato M., Wilhelmi M. R. (2014). Niveles de algebrización de la actividad matemática escolar. Implicaciones para la formación de maestros [Algebrization levels of school mathematics activity. Implication for primary school teacher education]. Enseñanza de las Ciencias, 32(1), 199-219. https://raco.cat/index.php/Ensenanza/article/view/287515

Godino J. D., Aké L., Contreras A., Estepa A., Blanco T. F., Neto T., Wilhelmi M.R., Diaz C., Oliveras M. L., Lacasta E., Lasa A. (2015). Diseño de un cuestionario para evaluar conocimientos didácticomatemáticos sobre razonamiento algebraico elemental [Designing a questionnaire for assessing the didactic-mathematical knowledge on elementary algebraic reasoning]. Enseñanza de las Ciencias, 33(1), 127-150. https://raco.cat/index.php/Ensenanza/article/view/288575

Godino J. D., Wilhelmi M. R., Neto T., Contreras A., Lasa A., Blanco T. F., Estepa A., Batanero C. (2015). Evaluación de conocimientos didáctico - matemáticos sobre razonamiento algebraico elemental de futuros maestros / Assessing the didactic - mathematical knowledge of prospective primary school teachers on elementary algebraic reasoning. Revista de educación, 370, 199-228. https://doi.org/10.4438/1988-592X-RE-2015-370-303

Gras R., Suzuki E., Guillet F., Spagnolo F. (Ed.) (2008). Statistical Implicative Analysis. Theory and Applications. Springer. 
Ministerio de Educación y Ciencia (MEC) (2015). Real Decreto 1105/2014, de 26 de diciembre, por el que se establece el currículo básico de la Educación Secundaria Obligatoria y del Bachillerato [Basic curriculum for Compulsory Secondary Education and the Higth School in Spain]. BOE 3, de 3 de enero. https://www.boe.es/buscar/pdf/2015/BOE-A-2015-37-consolidado.pdf

Roa R., Batanero C., Godino J.D. (2001). Dificultad de los problemas combinatorios en estudiantes con preparación matemática avanzada [Difficulty of combinatorial problems in students with advanced mathematical background]. Números 47, 33-47, http://sinewton.es/revista_numeros/047

Saragosa H., Ferreira, D. (2020). Abracadabra: mathematics in a magic trick. South Florida Journal of Development, 1(3), 122-127. https://doi.org/10.46932/sfjdv1n3-007

Vergnaud G. (1981) Quelques orientations théoriques et méthodologiques des recherches françaises en Didactique des mathématiques [Some theoretical and methodological orientations of French research in Mathematics Education]. RDM 2(2), 215-232. https://n9.cl/unzug

Wilhelmi M. R. (2004). Combinatoria y probabilidad [Combinatorics and probability]. Universidad de Granada. https://www.ugr.es/ batanero/pages/ARTICULOS/librowhilhelmi.pdf 